\title{
Correlation of mixed venous and central venous oxygen saturation and its relation to cardiac index
}

\author{
M. N. Ramakrishna, Devi Prasad Hegde, G. N. Kumaraswamy, Ratan Gupta, T. N. Girish
}

\begin{abstract}
ํํㄴ
Background and Aim: The clinical applicability of substitution of central venous oxygen saturation for mixed venous oxygen saturations in monitoring global tissue hypoxia is still a matter of controversy. Hence aim of the study is comparison of paired samples of mixed venous and central venous oxygen saturation and comparison in relation to cardiac index in varying hemodynamic conditions. Materials and Methods: Prospective clinical observation: Postoperative cardiac surgical ITU: 60 adult patients, $>18$ years of age of either sex: A PAC was inserted through ${ }^{\oplus}$ IJV, triple lumen catheter was inserted through ${ }^{\circledR}$ IJV. Blood samples were taken from distal tip of PAC and central venous catheters. An arterial blood sample was drawn from either radial or femoral arterial line. Measurements: Continuous cardiac output monitoring. Analysis of blood samples for hemoglobin concentration and oxygen saturation. Mixed venous oxygen saturations and central venous oxygen saturations were compared. The study was carried over a period of $30 \mathrm{~h}$ in the postoperative period and samples were taken at $6 \mathrm{~h}$ intervals. Patients were classified into three groups as follows depending on the $\mathrm{Cl}$ : Low $\left(<2.5 \mathrm{~L} / \mathrm{m}^{2}\right)$, medium $\left(2.5-4 \mathrm{~L} / \mathrm{m}^{2}\right)$, high $(>4 \mathrm{~L}$ / $\left.\mathrm{m}^{2}\right)$ and correlated with $\mathrm{Svo}_{2}$ and $\mathrm{Scvo}_{2}$. Results: 298 Comparative sets of samples were obtained. Svo $\mathrm{was}_{2}$ consistently lower than $\mathrm{Scvo}_{2}$ throughout the study period. The difference was statistically significant. By using Bland - Altman plot, the mean difference between $\mathrm{SvO}_{2}$ and $\mathrm{Scvo}_{2}\left(\mathrm{SvO}_{2}-\mathrm{Scvo}_{2}\right)$ was $-2.9 \% \pm 5.14$ and confidence limits are $+7.17 \%$ and $-12.97 \%$. The co-efficient $r$ is $>0.7$ throughout the study period for all paired samples. The correlation $\mathrm{SvO}_{2}$ and $\mathrm{Scvo}_{2}$ with cardiac index in all the three groups were >0.7. Conclusion: $\mathrm{Scvo}_{2}$ and $\mathrm{SvO}_{2}$ are closely related and are interchangeable. Even though individual values differ trends in $\mathrm{ScvO}_{2}$ may be substituted for trend in $\mathrm{SvO}_{2}$

Key words: Cardiac index, central venous oxygen saturation, mixed venous oxygen saturation, shock
\end{abstract}

\section{Introduction}

Shock is defi ned as the presence of global tissue hypoxia secondary to an imbalance between systemic oxygen delivery and demands. The pathological processes involved in shock are complex and varied. Clinical indicators of shock that are used in the early

\section{From:}

Consultant Intensivist, Adult ITU, Narayana Hrudayalaya Institute of Medical Sciences, 258/A, Bommasandra, Anekal Taluk, Bangalore, India

Correspondence:

Dr. MN Ramakrishna, No. 77, $4^{\text {th }}$ Cross, $3^{\text {rd }}$ Main, Duo Heights Residential Layout, Devarachikkanahalli, Begur Post, Bangalore - 68, India. E-mail: manvaram@yahoo.com phase of resuscitation include heart rate, blood pressure urine output and mentation and skin temperature. These variables are prone to compensatory mechanism and are late signs of adequate oxygen delivery and even if normalized, global tissue hypoxia still exists. Biochemical estimates of shock include serum lactate, ph, base deficit and anion gap in common with other global indices, which may be normal in the presence of significant regional ischemia and subject to a time delay and cannot be used for continual monitoring. The global tissue hypoxia if left untreated, leads to anaerobic metabolism and oxygen debt. The magnitude 
and duration of oxygen debt have been implicated in the development of multi system organ failure and increased mortality. This had lead to further investigation into more invasive means of assessing the adequacy of $\mathrm{O}_{2}$ delivery and consumption.

\section{Mixed Venous Oxygen Saturation $\left(\mathrm{Svo}_{2}\right)$}

The measurement of mixed venous oxygen saturation is used as a surrogate for the balance between systemic oxygen delivery and consumption. The clinical advantage of monitoring $\mathrm{SvO}_{2}$ is that unlike biochemical markers, it is not subject to a significant time delay. Declines in $\mathrm{Svo}_{2}$ preceded the fall of myocardial function and shock although physiological signs were within normal limits. It is a predictor of poor outcome in postoperative cardiothoracic patients, septic shock and cardiogenic shock. The technique also lends itself to continuous measurements by means of reflection spectrophotometry.

\section{Limitations of Mixed Venous Measurements}

Measurements of $\mathrm{SvO}_{2}$ requires placement of a PA catheter with a risk versus benefit relation that is still a matter of controversy. It is only possible to obtain mixed venous blood from a PAC which limits the use of $\mathrm{SvO}_{2}$ to an intensive care setting. Information from $\mathrm{SvO}_{2}$ will only be available after ICU admission and once resuscitation is already underway, hence there may be considerable delay in its application and this may have several implications. A number of well-conducted randomized control trials have examined the effectiveness of PAC in the treatment of critical illness and have failed to identify outcome improvements using PAC.

\section{Central Venous Oxygen Saturation $\left(\mathrm{Scvo}_{2}\right)$}

Central venous catheterization is a very common procedure in critically ill patients and is often done in other settings such as the emergency departments. Therefore measurement of $\mathrm{Scvo}_{2}$ seems to be an attractive alternative to monitoring $\mathrm{Svo}_{2}$ because it can be performed more easily, is less risky and less costly.

\section{Materials and Methods}

This study is a prospective observational study done on patients who underwent cardic surgery in Narayana Hrudayalaya Institute of Medical Science and were admitted in Adult Intensive Therapy unit post operatively.
We enrolled patients of either sex who were $>18$ years of age.

The study was conducted only in the postoperative period. After receiving patient in the ICU, Continuous Cardiac output monitor was connected and three simultaneous blood samples were taken after confirming proper pulmonary artery pressure waves, central venous pressure waves and arterial pressure waves on the monitor, before radiological confirmation of the catheter position. Multiorificed CV catheter 7.5 F was inserted via $(\mathrm{R})$ IJV and CCO monitoring catheter was introduced through 8.5F PA sheath in the (R) IJV.

First $3-5 \mathrm{ml}$ of blood drawn from each sample was discarded to prevent contamination with the flushing fluid. Three blood samples were collected simultaneously.

1. Distal tip of the PA catheter for mixed venous $\mathrm{O}_{2}$ saturation. It was collected when the pulmonary artery catheter was deflated to avoid contamination of the distal port sample with pulmonary capillary blood

2. Distal tip of the triple lumen central venous catheter for central venous oxygen saturation.

3. Arterial blood sample either from radial or femoral arterial line.

A standard volume of $1.5 \mathrm{ml}$ blood was obtained from each site. Blood samples were analyzed for estimated oxygen saturation using a standard blood gas analyzer (Bayer Health Care).

Hemoglobin, partial pressure of carbon dioxide were recorded from arterial sample. Oxygen saturation from pulmonary artery sample $\left(\mathrm{Svo}_{2}\right)$ and central venous sample $\left(\mathrm{Scvo}_{2}\right)$ were also recorded. Cardiac index was noted. The study was carried over for a period of $30 \mathrm{hs}$ in the post operative period and blood samples were taken as above mentioned at $6 \mathrm{~h}$ interval.

Exclusion criteria: Arterial samples which shows hemoglobin of $<9 \mathrm{gm}$.\%, partial pressure of oxygen $<90$ mmhg, partial pressure of carbon dioxide $>45 \mathrm{mmhg}$ and valve incompetecies were excluded.

\section{Data analysis}

Paired student $t$ test was used to compare $\mathrm{Svo}_{2}$ and $\mathrm{ScvO}_{2}$ and to determine whether the mean differences 
were significantly different from zero [Figure 1].

Values were presented as mean \pm SD unless otherwise stated.

Pearson correlation coefficients between $\mathrm{SvO}_{2}$ and $\mathrm{ScvO}_{2}$ were determined and compared in different cardiac index groups.

For all statistical procedures a " $P$ ' value $<0.05$ was considered significant.

Further more, $95 \%$ limits of $\mathrm{Cl}$ were calculated as bias \pm 1.96 SD.

Paired samples were compared using Bland Altmann plotting and linear correlation [Figure 2].

\section{Results}

We enrolled 60 patients in the study of whom five were women [Table 1].

In our study, partial pressure of carbon dioxide and hemoglobin were kept relatively constant as the oxygen saturations tend to change depending on these values [Table 2].

\begin{tabular}{lc}
\hline Table 1: Demographic profile \\
\hline Age & 56.6 years $(33-73$ years $)$ \\
Male/female & $55: 5$ \\
Ejection fraction & $38 \%(20-50 \%)$ \\
$\mathrm{FiO}_{2}$ & $0.5(0.4-0.6)$ \\
$\mathrm{Po}_{2}(\mathrm{mmhg})$ & $115 \pm 20$ \\
$\mathrm{PcO}_{2}(\mathrm{mmhg})$ & $38 \pm 5$ \\
$\mathrm{Hb}(\mathrm{gm} . \%)$ & $11 \pm 2$ \\
\hline
\end{tabular}

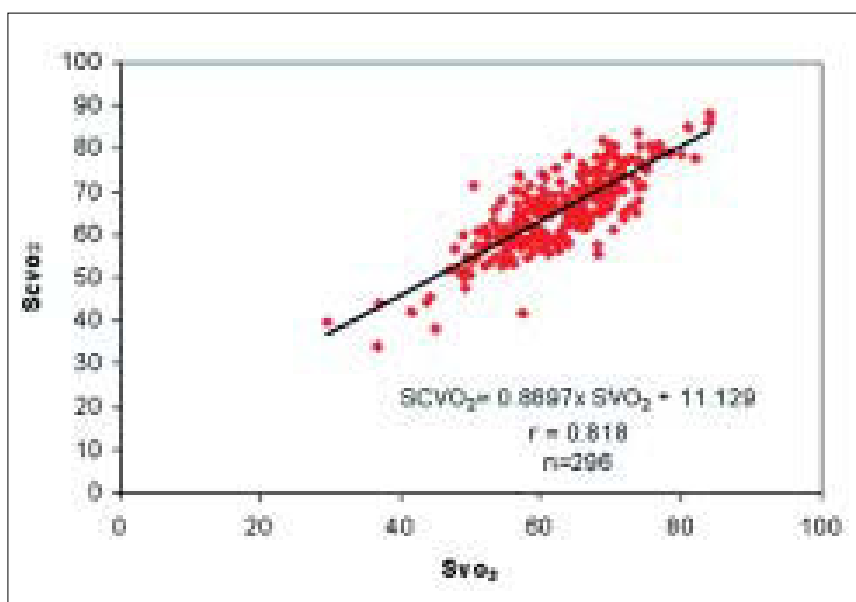

Figure 1: Linear correlation of paired $\mathrm{Scvo}_{2}$ and $\mathrm{Svo}_{2}$ measurements for 296 paired samples

$\mathrm{ScvO}_{2}$ increases by $0.87 \%$ for every unit increase in $\mathrm{SvO}_{2}$

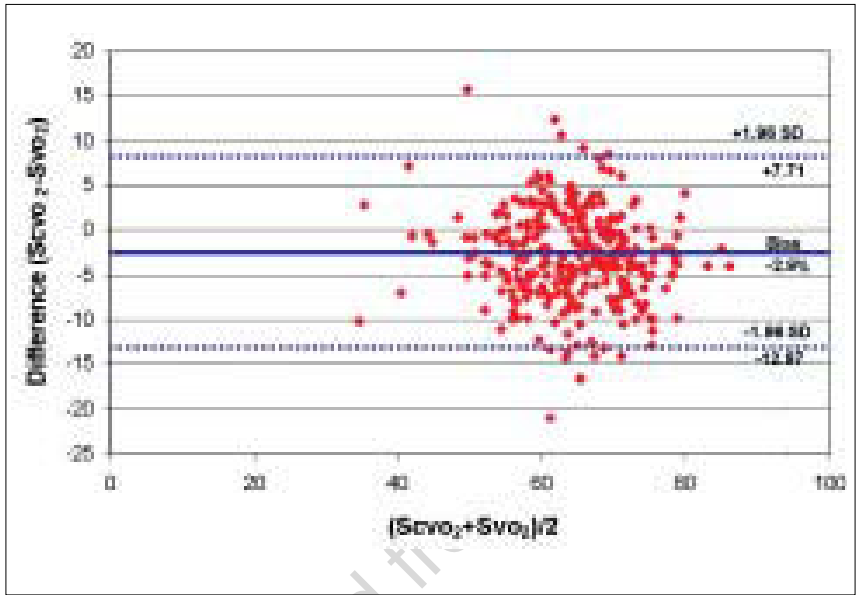

Figure 2: Bland and Altman Plot of the differences between mixed venous oxygen saturation and central venous oxygen saturation against the mean values. The unbroken line indicates mean difference and broken line indicates $95 \%$ limits of agreement (mean $\pm 1.96 \mathrm{SD})$

Mean value $-2.9 \%$, precision \pm 5.14 , confidence limits ( \pm 1.96 SD) i.e., $+7.17 \%$ and $-12.97 \%$

Fig 2 : Any systematic pattern is not observed in this plot. Values are equally distributed between the bias lines. Very few number of observations have crossed confidence limits indicating that $\mathrm{Scvo}_{2}$ and $\mathrm{SvO}_{2}$ values are replaceable [Table 5].

The mean ejection fraction was $38 \%$. All surgeries were done on cardio pulmonary bypass.

All patients required mechanical ventilation and ionotropes for a minimum period of 24 hours [Tables 3 and 4.

\section{Discussion}

The relationship between $\mathrm{Scvo}_{2}$ and $\mathrm{SvO}_{2}$ has been examined in numerous studies with controversial conclusions. But in this study, the investigations were conducted in a post-operative cardiac ICU setting, where the entire scenario of the study is different from other medical or trauma or surgical patients, as postoperative cardiac surgical patient behave differently. Hemodynamics of these patients in the immediate postoperative period will have an extremely labile course due to various causes during which time the investigations were conducted to compare the individual values as well as trends of central venous and mixed

Table 2: Surgical procedures involved in the study group

CABG 34

CABG + LV aneurysmorraphy 12

LV aneurysmorraphy

MVR

CABG: Coronary artery bypass graft 
Table 3: For the group as a whole, the values for $\mathrm{Svo}_{2}$ were lower than those of $\mathrm{Scvo}_{2}(P<0.001)$

\begin{tabular}{lcccc}
\hline & $\begin{array}{c}\text { Svo }_{2} \\
\text { (Mean } \pm \text { SD) }\end{array}$ & $\begin{array}{c}\text { Scvo }_{2} \\
\text { (Mean } \pm \text { SD) }\end{array}$ & $\begin{array}{c}\text { Correlation } \\
\text { Coefficients }\end{array}$ \\
O hours & $63.55 \pm 10.14$ & $65.97 \pm 10.45$ & 0.870 & $P<0.001$ \\
6 hours & $61.13 \pm 8.61$ & $63.95 \pm 9.01$ & 0.867 & $P<0.001$ \\
12 hours & $63.28 \pm 7.12$ & $65.76 \pm 6.93$ & 0.766 & $P<0.001$ \\
18 hours & $64.30 \pm 6.30$ & $66.57 \pm 6.47$ & 0.729 & $P<0.001$ \\
24 hours & $63.30 \pm 7.40$ & $67.73 \pm 9.60$ & 0.712 & $P<0.001$ \\
30 hours & $64.50 \pm 7.88$ & $68.13 \pm 8.16$ & 0.812 & $P<0.001$ \\
\hline
\end{tabular}

Table 4: Correlation of $\mathrm{Svo}_{2}$ versus $\mathrm{Scvo}_{2}$ in relation to cardiac index

\begin{tabular}{lccc}
\hline Time in hours & $\begin{array}{c}<.5 \\
\mathbf{L} / \mathbf{m i n} / \mathbf{m}^{2}\end{array}$ & $\begin{array}{c}\mathbf{2 . 5}-\mathbf{4 L} / \\
\mathbf{m i n} / \mathbf{m}^{\mathbf{2}}\end{array}$ & $\begin{array}{c}>\mathbf{4 L} / \mathbf{m i n} / \\
\mathbf{m}^{\mathbf{2}}\end{array}$ \\
0 hours & 0.78 & 0.85 & 0.99 \\
6 hours & 0.81 & 0.87 & 0.75 \\
12 hours & 0.86 & 0.71 & $\mathrm{Nil}$ \\
18 hours & 0.84 & 0.72 & $\mathrm{Nil}$ \\
24 hours & 0.86 & 0.70 & $\mathrm{Nil}$ \\
30 hours & 0.74 & 0.84 & $\mathrm{Nil}$
\end{tabular}

Correlation coefficient $r$ for $\mathrm{SvO}_{2}$ versus $\mathrm{ScvO}_{2}$ is $>0.70$ in all cardiac index groups at all time intervals. The sample size in high $\mathrm{Cl}$ group $\left(>4 \mathrm{~L} / \mathrm{min} / \mathrm{m}^{2}\right)$ after $12 \mathrm{~h}$ were limited and so is not considered for data analysis.

Table 5: Mean differences and confidence intervals

\begin{tabular}{lcc}
\hline Time in hours & Mean differences & Confidence interval \\
0 hours & $-2.3 \pm 5.2$ & -3.71 to -1.01 \\
6 hours & $-2.8 \pm 4.56$ & -3.97 to -1.63 \\
12 hours & $-2.4 \pm 4.8$ & -3.67 to -1.1 \\
18 hours & $-2.2 \pm 4.7$ & -3.34 to -0.91 \\
24 hours & $-4.7 \pm 6.27$ & -6.46 to -2.08 \\
30 hours & $-3.35 \pm 4.8$ & -5.25 to -1.4 \\
\hline
\end{tabular}

venous oxygen saturations in relation to cardiac index at that point of time [Figure 3]. The correlation between $\mathrm{SvO}_{2}$ and $\mathrm{Scvo}_{2}$ in the postoperative period of cardiac surgical patients is not adequately analyzed in previous studies especially in Indian population. Hence in our study, the $\mathrm{SvO}_{2}$ and $\mathrm{Scvo}_{2}$ were analyzed along with continuous cardiac output monitoring in these patients.

It is observed that $\mathrm{Svo}_{2}$ values were always lower than that of $\mathrm{Scvo}_{2}$ at various intervals and in different cardiac output values. Scheinman et $\mathrm{al}^{\left[{ }^{1]}\right.}$ compared $\mathrm{Scvo}_{2}$ and $\mathrm{SvO}_{2}$ in critically ill patients and found $\mathrm{Scvo}_{2}$ levels were consistently higher than $\mathrm{Svo}_{2}$ and changes in $\mathrm{Scvo}_{2}$ in

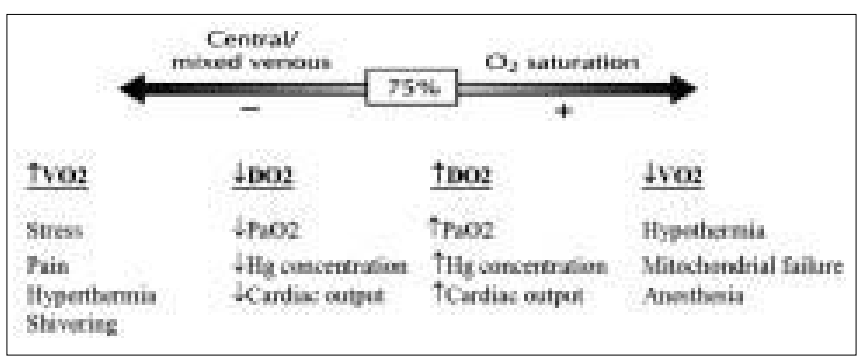

Figure 3: Variables that affect mixed /central venous $\mathrm{O}_{2}$ saturation. shock reflect changes in $\mathrm{Svo}_{2}(r=0.90)$ even though correlation decreases with onset of shock. This is observed as the mixed venous samples were obtained from pulmonary artery after complete mixing of venous blood with different oxygen saturations coming from various regions of body including that of coronary sinus, whose oxygen saturations were very low as the myocardium extract maximum amount of oxygen from the blood, where as $\mathrm{Scvo}_{2}$ obtained from superior venacava indicates only the balance between oxygen delivery and consumption in the cranial part of the body, mainly in the brain which has decreased oxygen saturation as a result of anaesthesia.

Now various factors including peripheral utilization of $\mathrm{O}_{2}$ in conditions such as sepsis or low cardiac output can affect the values of $\mathrm{Svo}_{2}$ which can alter the relationship between $\mathrm{Scvo}_{2}$ and $\mathrm{SvO}_{2}$. In such conditions it becomes highly irrelevant to consider that $\mathrm{Svo}_{2}$ values can be substituted by $\mathrm{Scvo}_{2}$. It has been demonstrated by many authors in various studies that under stressful conditions the $\mathrm{Svo}_{2}$ values cannot be replaced by $\mathrm{Scvo}_{2}$ values. Scheinman et $a^{{ }^{11]}}$ (no CHF/shock; $r=0.99$; CHF, $r=0.59$; cardiogenic shock, $r=0.55$ ) and Lee et $a^{l^{2}}$ (nonshock, $r=0.88$; shock, $r=0.73$ ) showed that there was poor correlation between $\mathrm{Scvo}_{2}$ and $\mathrm{Svo}_{2}$ when shock and heart failure were present in critically ill patients.

In contrast to above findings many other authors have found that the correlation between $\mathrm{ScvO}_{2}$ and $\mathrm{SvO}_{2}$ were clinically acceptable even under various stressful conditions. JC Berridge et a ${ }^{[3]}$ studied influence of cardiac output on the correlation between $\mathrm{SvO}_{2}$ and $\mathrm{Scvo}_{2} \mathrm{He}$ found that correlation coefficient for the three groups studied as per cardiac output were statistically significant (Low $\mathrm{Cl}=0.95, \bmod \mathrm{Cl}=0.88$, high $\mathrm{Cl}=0.95 ; P<0.001)$. Ladakis et $a^{[4]}$ compared central and mixed venous oxygen saturation in critically ill patients and concluded that $\mathrm{Scvo}_{2}$ and $\mathrm{SvO}_{2}$ are closely related and interchangeable for initial evaluation of critically ill patients. In our study we found a good correlation coefficient between $\mathrm{Scvo}_{2}$ and $\mathrm{SvO}_{2}$ throughout the study. We have also observed that correlation coefficient was good even in various cardiac index group (3 groups: low $<2.5 \mathrm{~L} / \mathrm{m} / \mathrm{m}^{2}, \mathrm{r}>0.74$; moderate $2.5-4 \mathrm{~L} / \mathrm{m} / \mathrm{m}^{2}, \mathrm{r}>0.70$; Good $>4 \mathrm{~L} / \mathrm{m} / \mathrm{m}^{2}, r>0.75$ ) But the most important observations made in our study was that even when the values of $\mathrm{Scvo}_{2}$ and $\mathrm{Svo}_{2}$ differed, the trend in the 
changes of values of both paralleled under the similar cardiac index and was corresponding to each other. Dueck et $a^{[5]}$ compared the trends of $\mathrm{Scvo}_{2}$ with $\mathrm{Svo}_{2}$ during varying hemodynamic conditions. They found that correlation between changes of $\mathrm{Scvo}_{2}$ and $\mathrm{SvO}_{2}$ were clinically acceptable ( $r=<0.75, P=0.001)$ to which our study finding corres ponds very well.

Our study reveals a good correlation between the trends of $\mathrm{Scvo}_{2}$ and $\mathrm{SvO}_{2}$, Which is in accordance with several previous studies (Reinhart et al, ${ }^{[6]}$ Scheinman et al, ${ }^{[1]}$ Reinhart et al, ${ }^{[7]}$ Dueck et al, ${ }^{[5]}$ Tahvanainen et $a^{[8]}$ ) Scheinman et $a^{{ }^{11]}}$ even though found a poor correlation between absolute values in patients with severe heart failure or shock, observed a better correlation between changes of $\mathrm{Scvo}_{2}$ and $\mathrm{Svo}_{2}$. Reinhart et $\mathrm{al}^{[7]}$ in an animal model demonstrated a close tracking of the $\mathrm{O}_{2}$ saturations continuously measured in the PA and SVC across a wide range of hemodynamic conditions. In a recent study the same group could confirm these findings in critically ill patients. ${ }^{[8]}$ Tahranainen et a ${ }^{[8]}$ found a significant correlation between PA blood samples and both SVC and RA blood samples during subsequent changes of $\mathrm{O}_{2}$ saturations in critically ill patients. In a similar way, Dueck et $a^{\left[{ }^{6]}\right.}$ found excellent correlation between changes in the trends of $\mathrm{O}_{2}$ saturation between $\mathrm{SvO}_{2}$ and $\mathrm{ScvO}_{2}$ during varying hemodynamic conditions. These data suggest that $\mathrm{Scvo}_{2}$ is equivalent to $\mathrm{SvO}_{2}$ in the course of clinical decisions as long as absolute values are not required, which is well supported by our study data.

\section{Conclusion}

The aim of our study is not to replace the values of $\mathrm{SvO}_{2}$ by $\mathrm{Scvo}_{2}$, but rather study the applicability of the central venous oxygen saturations in the setting of various hemodynamic conditions and find out the possibility of its usage in certain conditions where PA catheter usage is limited or not advised. It is well known and proven that insertion as well as maintaining PA catheter carries its own disadvantages and contraindications because of which its usage has been restricted mostly to cardiac centers only.
Our study intended to find out the clinical applicability of using $\mathrm{ScvO}_{2}$ instead of $\mathrm{SvO}_{2}$ in these settings which can be of great value in treating critically ill patients.

After comparing and studying the data available from our study, we conclude that despite some differences between absolute values of $\mathrm{Svo}_{2}$ and $\mathrm{Scvo}_{2}$ in patients with varying haemodynamic situations, there was a reasonably good correlation between these values and trends. Hence, trend in $\mathrm{Scvo}_{2}$ may be used as a surrogate variable for the trend in $\mathrm{Svo}_{2}$ which can be valuable in treating critically ill patients.

\section{References}

1. Scheinman MM, Brown MA, Rapaport E. Critical assessment of use of central venous oxygen saturation as a mirror of mixed venous oxygen in severely ill cardiac patients. Circulation 1969;40:165-72.

2. Lee J, Wright F, Barber R, Stanley L. Central venous oxygen saturation in shock: A study in man. Anesthesiology 1972;36:472-8.

3. Berridge JC. Influence of cardiac output on the correlation between mixed venous and central venous oxygen saturation. Br J Anaesth 1992;69:409-10.

4. Ladakis C, Myrianthefs P, Karabinis A, Karatzas G, Dosios T, Fildissis $G$, et al. Central venous and mixed venous oxygen saturation in critically ill patients. Respiration 2001;68:279-85.

5. Dueck $\mathrm{MH}$. Trends but not individual values of central venous oxygen saturation agree with mixed venous oxygen saturation during varying hemodynamic conditions. Anaesthesiology 2005;249-57.

6. Reinhart K, Rudolph T, Bredle DL, Hannemann L, Cain SM. Comparison of central-venous to mixed-venous oxygen saturation during changes in oxygen supply/demand. Chest 1989;95:1216-21.

7. Reinhart K, Kuhn HJ, Hartog C, Bredle DL. Continuous central venous and pulmonary artery oxygen saturation monitoring in the critically ill. Intensive Care Med 2004;30:1572-8.

8. Tahvanainen J, Meretoja O, Nikki P. Can central venous blood replace mixed venous blood samples? Crit Care Med 1982;10:758-61.

Source of Support: Nil, Conflict of Interest: None declared. 